\title{
UMA PROPOSTA PARA A GESTÃO DOS RESÍDUOS SÓLIDOS NO INTERIOR DO ESTADO DO PARANÁ: ESTUDO PARA IMPLANTAÇÃO DE UMA USINA DE COMPOSTAGEM
}

\author{
A PROPOSAL FOR THE MANAGEMENT OF SOLID WASTE \\ WITHIN THE STATE OF PARANÁ: STUDY FOR DEPLOYMENT \\ OF A COMPOSTING PLANT
}

\section{Rafaela Franqueto}

Doutoranda em Engenharia Ambiental, Fundação Universidade Regional de Blumenau (FURB). E-mail: rafaela.eng@meioambiente.e ng.br

Angelo Antonio Delponte Mestrando em Bioenergia, Universidade Estadual do Centro-Oeste (UNICENTRO), Irati (PR). E-mail: angeloadelponte@gmail.com

\section{Renan Franqueto} Graduando em Engenharia Civil, Unidade de Ensino Superior Vale do Iguaçu (UNIGUAÇU), União da Vitória (PR). E-mail: renanfranqueto@hotmail

\section{RESUMO}

O presente trabalho apresenta um estudo de caso de implantação de uma unidade de compostagem, tendo como objetivo desenvolver uma análise técnica simplificada e econômica para o aproveitamento de resíduos de aviários, como base para um modelo operacional focado na promoção deste uso como preceitos para diminuição do passivo operacional sistêmico das entidades empresariais. Constatou-se nesse projeto estão inclusos a definição da compostagem, os princípios da disposição das carcaças em um meio de sustentabilidade, também demonstra os métodos de armazenamento, processo de produção do material que conforme análises laboratoriais poderão ser de ótima condição de produtividade para o solo e assim de excelente insumo para lavouras.

Palavras-chave: Compostagem, gestão ambiental, ativo ambiental.

\section{ABSTRACT}

This work presents a study of the implementation of the case of a composting plant, aiming to develop a simplified and economic technical analysis for the use of poultry waste as a basis for an operational model focused on promoting this use as precepts to decreased systemic operational liabilities of business entities. It was found in this design are included in the definition of composting, the principles of the arrangement of substrates in a medium sustainability also demonstrates methods of storage, manufacturing process of the material as laboratory tests could be of great productivity condition of the soil and thus excellent input for crops.

Keywords: Composting, environmental management, environmental asset. 


\section{INTRODUÇÃO}

O conjunto de ações empreendidas pela sociedade ou parte dela, com o objetivo de proteger, restaurar, conservar e utilizar de maneira sustentável o meio ambiente pode ser definido como gestão ambiental (PALHARES; MIRANDA, 2007).

O crescimento da população fez com que o aumentassem os resíduos tanto na área urbana quanto na rural, pois novos empreendimentos estão sendo construídos, ou ampliados, e em muitos casos inovando a produção. Conforme Poleto (2010), nunca foi produzida tamanha quantidade de resíduos sólidos como atualmente. A composição e a quantidade dos resíduos produzidos estão diretamente relacionadas ao modo de vida dos povos, à sua condição socioeconômica e à facilidade de acesso aos bens consumo.

Partindo do fato de que a participação dos materiais orgânicos representa 51,4\% do total de resíduos sólidos urbanos coletados no país (ABRELPE, 2011), uma grande parte deste material poderia ser passível de reciclagem por meio do processo de compostagem. (CHERMONT, 2000). Este método de tratamento constitui-se numa forma viável economicamente e simples, quando comparado a outras formas de tratamento de resíduos, sendo extremamente eficaz, pois redireciona o material que iria ser aterrado para um uso mais nobre. O lixo que é destinado a compostagem é aquele advindo do uso domiciliar, rico em cascas de frutas, de verduras, restos de alimentos, etc., podendo conter também folhagens, podas de árvores que são muito importantes na produção de compostos orgânicos (SEMA, 2008, p. 112). Quando não há reciclagem de resíduos orgânicos, toda essa matéria orgânica gerada que poderia ser utilizada para recondicionar o solo é desperdiçada indo parar em aterros, lixões entre outros.

Uma instalação de compostagem só deve ser implantada se estudos técnicos e econômicos assim o indicarem, levando em conta a disponibilidade de área para aterros, mercado para o composto, custo da instalação etc. (RESOL, 2011). A gestão ambiental em granjas aviárias é de grande importância, visto que compõe um dos elos da cadeia produtiva de animais e merece destaque. Atualmente, o modelo de produção é caracterizado pela criação intensiva e em confinamento, o que concentra grande número de animais em áreas reduzidas, aumentando ainda mais os riscos de contaminação ambiental (KUNZ et al., 2004).

Um dos grandes problemas na implantação do método da compostagem no país é a falta de informação sobre os benefícios da utilização dos compostos por parte 
significativa da população. Ainda atualmente muitos resíduos não possuem destinação final adequada, assim alterando o meio ambiente. Quando há uma preocupação com a destinação correta, surgem então os investimentos, a mão-de-obra entre outros fatores que deveram ser estipulados pela empresa.

O objetivo deste trabalho foi estudar a viabilidade técnica e econômica para implantação de uma unidade de compostagem para o tratamento de resíduos orgânicos de um abatedouro de aviário.

\section{MATERIAL E MÉTODOS}

Este levantamento foi realizado na empresa que propõe a instalação da unidade de compostagem. A empresa prestará o serviço de coleta, transporte e o tratamento dos resíduos oriundos da atividade aviária. Para isso o processo de compostagem de resíduos demandará o treinamento dos funcionários para o conhecimento e domínio do sistema, pois haverá procedimentos adequados em função dos diferentes tipos e quantidades de resíduos.

Algumas considerações relevantes devem ser consideradas para a tomada de decisão que é a de compreender na sua plena extensão como o problema ocorre. A isso se dá o nome de logística. Assim qualquer que seja o método para a destinação de resíduos, sempre haverá necessidade de:

- Coletar os resíduos nas unidades geradoras;

- Transportar os resíduos de maneira organizada e segura para o local escolhido;

- Estar preparado para agregar ao processo alguns insumos, como água e/ou dejetos líquidos e ter estoques disponíveis de materiais coadjuvantes como maravalha, enzimas, ou materiais compostáveis.

A compostagem como alternativa para a destinação dos resíduos é um processo em fluxo contínuo que permite o livre deslocamento entre o resíduo gerado até o processo de tratamento. Permite que todos os resíduos independentes do momento em que ocorram à geração possam ser encaminhados à destinação onde encontrem condições plenas de recebê-los. 
Quanto maior a geração de resíduos mais se evidência a vantagem do processo em fluxo contínuo. Enfim serão comentadas todas as etapas da realização da compostagem para o tratamento de resíduos orgânicos.

\section{RESULTADOS E DISCUSSÃO}

\subsection{RESÍDUOS UTILIZADOS NA COMPOSTAGEM E O ARMAZENAMENTO}

Foram misturados os resíduos como - Esterco de animais, suínos, aves; qualquer tipo de plantas, pastos, cascas, folhas verdes e secas; chorume de aterro, lodo de lagoas de estabilização (sendo o lodo constituído de mais de 95\% de água); casca de ovo; pintinhos mortos; de abatedouros da região (vísceras de animais), e pêlos, lãs, couros.

Foram utilizados $70 \%$ de cama de aviário e outros resíduos sólidos, e 30\% de resíduos líquidos. Estas porcentagens poderão variar de um resíduo para outro tipo de resíduo.

O armazenamento dos resíduos foi em local coberto, evitando o contato com a chuva. Este armazenamento foi dividido em: resíduos líquidos no tanque de lodo, e os resíduos sólidos na caixa de armazenamento.

\subsubsection{Tanque de Lodo}

O lodo oriundo de lagoas de estabilização, e lodos ativados, de vários tipos de empreendimentos chega à unidade de compostagem e é despejado em um tanque, o qual mistura os resíduos: líquido e pastoso, para que possa haver uma homogeneização entre esses resíduos, e posteriormente será bombeado para a pinha de resíduos orgânicos. Esse lodo será misturado com os resíduos sólidos, os quais passa á absorver este lodo. A capacidade desse tanque será de $20 \mathrm{~m}^{3}$.

Este tanque de lodo é feito de concreto armado, para que esse tipo de efluente não entre em contato com o meio ambiente. Também há uma cobertura para que não aumente á quantidade de água no lodo. A mistura no fundo do tanque será feita por pás-mecânicas. O lodo será facilmente bombeado e não deverá prejudicar a bomba. Contudo este lodo será transportado para a leira. 
Foi utilizado o Cone Imhoff para medir a quantidade de lodo misturado com os resíduos sólidos. Este Cone Imhoff é graduado até $1000 \mathrm{ml}$, sendo muito usado em todos os laboratórios de pesquisas e estações de tratamento de esgotos.

Para este lodo chegar até a unidade de compostagem, foi necessário a utilização de um caminhão vácuo com capacidade de transportar 8 mil litros deste resíduo.

\subsubsection{Caixa de Armazenamento de Resíduos Sólidos}

O Caminhão Caçamba transporta os resíduos sólidos de onde são gerados os determinados resíduos até a caixa de armazenamento da unidade de compostagem. Além disso, este mesmo caminhão irá realizar as entregas do adubo vendido.

Esta caixa tem a capacidade de armazenar uma carga de resíduos sólidos, ou seja, $30 \mathrm{~m}^{3}$. As paredes são de formato de um quadrado, e na parte inferior é de formato cônico com uma rosca transportadora.

Quando o resíduo sólido passar a ser carregado pela esteira transportadora ele então será levado até a mistura com o lodo. Essa mistura ocorre por meio de um equipamento que contém uma élise que gira e mistura esses dois tipos de resíduos que caíram sobre a pilha de compostagem.

\subsection{LEIRAS ESTÁTICAS ACELERADAS}

O método adotado para compostagem é o de leiras estáticas aceleradas (GRIPPI, 2001, p. 34), o qual realiza o insuflamento de ar forçado na massa em degradação de várias leiras, tornando-se necessários equipamentos de controle, bem como de dispositivos adequados á perfeita difusão do ar na leira, que é conseguida com a utilização de tubulações de PVC de 20 milímetros, com pequenos furos a cada $15 \mathrm{~cm}$ um do outro. Um soprador de ar de 0,5 HP, soprando 2 minutos a cada 30 minutos. "O revolvimento será feito com a Máquina Bobcat”. Este método faz com que o revolvimento das leiras seja feito menos vezes, e consequentemente a diminuição de gastos com a mão de obra e equipamentos.

\subsubsection{Dimensionamento das Leiras}

Tamanho do pátio das leiras: $40 \mathrm{~m} \mathrm{x} 40 \mathrm{~m}$;

Serão 8 leiras; 
Cada leira: 1,50 m de altura; $3 \mathrm{~m}$ de largura; e $35 \mathrm{~m}$ de comprimento;

Volume: $78,75 \mathrm{~m}^{3} \times 8$ leiras $=630 \mathrm{~m}^{3}$

\subsection{PENEIRA ROTATIVA}

Os resíduos são encaminhados por uma esteira até a peneira rotativa, esta mesma deverá estar posicionada em um lugar alto para a Bobcat poder entrar em baixo da peneira a fim de retirar o adubo, e também à peneira rotativa deverá possuir uma cobertura.

Na peneira rotativa o adubo é peneirado separando dos materiais inertes (pedra, plástico, entre outros). Assim o material que permanecer embaixo da peneira é o adubo, já o que sair de um lado para outro da peneira, são materiais inertes.

O adubo é mantido em baías, separados por tipos de resíduos que foram misturados, e posteriormente serão realizados testes com amostra desses resíduos na unidade experimental.

Os materiais inertes ficam depositados em um canto do pátio até completar uma carga, e encaminhados para o aterro sanitário do Município, para servir de base das valas a fim de facilitar a movimentação do chorume. Entretanto esses resíduos inertes representarão uma pequena quantidade em relação aos orgânicos.

\subsection{O ADUBO ORGÂNICO}

O adubo orgânico traz muitos benefícios, como a geração de empregos e produtos mais saudáveis á mesa do consumidor. Além de se ter uma destinação correta dos resíduos orgânicos, aumenta da vida útil de aterros sanitário e industrial. Contudo o adubo orgânico oferece melhorias na qualidade das propriedades químicas, físicas e biológicas do solo:

A matéria orgânica composta se liga às partículas (areia, limo e argila), ajudando na retenção e drenagem do solo melhorando sua aeração; aumenta a capacidade de infiltração de água, reduzindo a erosão; dificulta ou impede a germinação de sementes de plantas invasoras; aumenta o número de minhocas, insetos e microorganismos desejáveis, devido à presença de matéria orgânica, reduzindo a incidência de doenças de plantas; mantêm a temperatura e os níveis de acidez do solo; ativa a vida do solo, favorecendo a reprodução de microorganismos benéficos às culturas agrícolas; aproveitamento agrícola da matéria orgânica; processo ambientalmente seguro; eliminação de patógenos. 
Em comparação com o adubo químico o adubo orgânico não causa esses malefícios:

- Uma parte é rapidamente absorvida pelas raízes das plantas causando expansão celular (as membranas celulares ficam mais finas), fazendo que aumente muito seu teor de água. Consequentemente as plantas ficam mais suscetíveis a pragas e doenças, além de menos saborosas e com seu teor nutritivo empobrecido.

- Outra parte (muitas vezes a maior parte) é lixiviada, ou seja, é levada pelas águas das chuvas e regas, indo poluir rios, lagos e lençóis freáticos, causando juntamente com os despejos de esgotos, a eutrofização dos corpos aquáticos-que é a morte de um rio ou lago por asfixia, pois os excessivos nutrientes além de estimularem um crescimento excessivo das algas, roubam para se degradarem, o oxigênio da água.

- Há ainda uma terceira parte que evapora, como no caso dos adubos nitrogenados (como o sulfato de amônio) que sob a forma de óxido nitroso pode destruir a camada de ozônio da atmosfera.

- Já o produto acabado e testado será então destinado à produção agrícola. Sendo comercializado tanto com pequenos até com grandes produtores rurais.

- A venda do adubo orgânico será feita por sacos e por granel. O mesmo caminhão que traz o resíduo fornecerá aos clientes os produtos da empresa.

De acordo com Pereira Neto (1999), o composto orgânico não tem e dificilmente terá problema de mercado no Brasil, pois, são várias as opções de uso para este produto. O adubo orgânico poderá ser encaminhado para aplicações e usos em atividades como: vendas em pequenas quantidades particulares, (para a população em geral); lojas de plantas ornamentais (floriculturas); horticultura; fruticultura; produção de grãos; parques, jardins e playground; projetos paisagísticos; reflorestamento; hortos e produção de mudas; recuperação de solos esgotados; controle de erosão, proteção de encostas e taludes; e cobertura de aterros, etc.

\subsubsection{Quantidade de Adubo Produzido}

O quadro abaixo representa a quantidade de adubo que será produzido. Sendo que a empresa só terá lucro a cada a partir de 3 meses, por causa do tempo que leva para os resíduos se decomporem. No término do período de compostagem o volume do adubo é a metade do volume de resíduos que chega na unidade de tratamento. 
Tabela 1 - Quantidade de adubo orgânico produzido

\begin{tabular}{ccc}
\hline Tempo de compostagem & Volume de resíduos & Volume de adubo \\
\hline $1^{\circ}$ mês & $210 \mathrm{~m}^{3}$ & $105 \mathrm{~m}^{3}$ \\
$2^{\circ}$ mês & $210 \mathrm{~m}^{3}$ & $105 \mathrm{~m}^{3}$ \\
$3^{\circ}$ mês & $210 \mathrm{~m}^{3}$ & $105 \mathrm{~m}^{3}$ \\
Total & $630 \mathrm{~m}^{3}$ & $315 \mathrm{~m}^{3}$ \\
\hline
\end{tabular}

Fonte: autores, 2017

De início a fabricação do adubo será a cada 3 meses, posteriormente pretende ampliar as instalações para que todo o mês o volume fabricado seja $315 \mathrm{~m}^{3}$.

\subsection{MEDIDAS MITIGADORAS}

São aquelas destinadas a prevenir impactos negativos ou reduzir sua magnitude. Nestes casos, é preferível usar a expressão 'medida mitigadora' em vez de 'medida corretiva', também muito usada, uma vez que a maioria dos danos ao meio ambiente, quando não podem ser evitados, podem apenas ser mitigados ou compensados.

Essas medidas mitigadoras servem para qualquer área, são as mínimas necessárias para esse tipo de empreendimento, portanto empresa não irá implantar a compostagem, em uma área que possa ocorrer algum dano ambiental.

\subsubsection{Controle de Patogênicos}

A maior parte dos patógenos é destruída a $55^{\circ} \mathrm{C}$; a eliminação total pode ser conseguida deixando o material atingir os $70^{\circ} \mathrm{C}$ durante 1 a 2 horas, o que exige uma operação atenta.

\subsubsection{Controle de Odores}

A maior parte dos problemas de odores nos processos de compostagem aeróbia estão associados ao desenvolvimento de condições anaeróbias na pilha de compostagem. Em grandes processos de compostagem aeróbia é comum encontrar fragmentos de revistas, livros e outros compostos orgânicos que não são compostados num espaço curto de tempo, e como o oxigênio nem sempre é suficiente, desenvolvem-se condições anaeróbias. Nestas circunstâncias, há produção de ácidos orgânicos que emitem odores intensos. Para minimizar os potenciais problemas de odores é importante reduzir o 
tamanho das partículas, retirar plásticos e outros materiais não biodegradáveis do material orgânico para compostar.

\subsubsection{Controle do Excesso de Chorume}

O pátio das leiras contará com as canaletas para recolher o chorume das leiras e então encaminhar até o tanque de chorume e água de chuva. Por meio da irrigação este efluente fornecerá umidade as leiras

OBS: Esse chorume surgirá quando houver excesso de chuva ou umidade vinda das leiras.

\subsection{INVESTIMENTOS}

Para a proposta de implantação de uma unidade de compostagem deverão saber quais serão os investimentos que o empreendimento deverá adotar como é observado na Tabela 2.

Tabela 2 - Investimento de uma usina de compostagem

\begin{tabular}{ll}
\hline EQUIPAMENTOS & CUSTOS $(\mathbf{R} \$ \mathbf{)}$ \\
\hline Escritório com banheiro & $5.000,00$ \\
Cerca próxima a compostagem & $3.000,00$ \\
Barracão pré-moldado & $30.000,00$ \\
Piso de concreto & $20.000,00$ \\
Caminhão vácuo & $70.000,00$ \\
Caminhão Caçamba & $40.000,00$ \\
Esteira de resíduos & $2.000,00$ \\
Tanque de lodo & $3.000,00$ \\
Caixa de armazenamento de resíduos sólidos & $5.000,00$ \\
Bomba para tanque de lodo & $2.000,00$ \\
Motor para a mistura & $2.000,00$ \\
Bomba para mistura na pilha & $2.000,00$ \\
Bombas para irrigação das leiras & 500,00 \\
Compressor de ar & $3.000,00$ \\
Tubulações para compressor de ar & 500,00 \\
Aquisição do terreno & $25.000,00$ \\
Peneira rotativa & $4.000,00$ \\
Maquina Bobcat e Carreta para transporte & $32.000,00$ \\
Total & $249.000,00$ \\
\hline
\end{tabular}

Fonte: autores, 2017 


\section{CONCLUSÃO}

O processo de compostagem gera um volume que é integralmente utilizado na unidade e pelos colaboradores, estando estruturado com uma lógica sistêmica. Entretanto o monitoramento do processo de compostagem não segue as recomendações encontradas na literatura, sendo o controle realizado de forma empírica. A capacitação dos colaboradores envolvidos no processo de compostagem é relativamente baixa para o nível de importância socioambiental da atividade exercida. A coleta seletiva serve de apoio à inclusão social, sendo praticada como um projeto de responsabilidade socioambiental.

Nesse projeto estão inclusos a definição da compostagem, os princípios da disposição das carcaças em um meio de sustentabilidade, também demonstra os métodos de armazenamento, processo de produção do material que conforme análises laboratoriais poderão ser de ótima condição de produtividade para o solo e assim de excelente insumo para lavouras.

Enfim além de se ter um método de disposição adequado, será de sustento para produções de alimentos, melhorando a capacidade do solo para produzir mais e em melhores condições de consumo evitando o uso de fertilizantes químicos que interferem na qualidade dos produtos plantados.

\section{REFERÊNCIAS}

ASSOCIAÇÃO BRASILEIRA DE EMPRESAS DE LIMPEZA PÚBLICA E RESÍDUOS ESPECIAIS. Panorama dos resíduos sólidos no Brasil. São Paulo, 2011.

CARTILHA DE LIMPEZA URBANA - Web Resol, 2011. Disponível em http://www.resol.com.br/cartilha4/tratamento_reciclagem.php. Acesso em 15 de agosto de 2011.

CHERMONT, Larissa. Educação Ambiental e Fontes de Financiamento. In: Simpósio Sobre a Reciclagem de Lixo Urbano para fins Industriais e Agrícolas, Belém, 1998. Anais: Belém, PA, Embrapa Amazônia Ocidental, 2000, p.201-202.

GRIPPI, S. Lixo, Reciclagem e sua História. Guia para as Prefeituras Brasileiras. Editora Interciência. Rio de Janeiro - RJ. 2001. 134p.

KUNZ, A.; SCHIERHOLT NETO, G. F.; NUNES, L. M. A.; OLIVEIRA, P.A. Estudo da relação maravalha/dejeto a diferentes umidades para incorporação de lodo de dejeto de suínos, Florianópolis, 2004. p.2193 - 2198. In: Anais..., Congresso Brasileiro de Ciência e Tecnologia em Resíduos e Desenvolvimento Sustentável, 2004, Florianópolis. 2004.

Disponível em https://www.ipen.br/biblioteca/cd/ictr/2004/ARQUIVOS\%20PDF/01/01-003.pdf> 
PALHARES, J. C. P.; MIRANDA, C. R. Gestão Ambiental da propriedade suinícola. In: SEGANFREDO, M. A. (Ed.). Gestão Ambiental na Suinocultura. Brasília, DF:Embrapa Informação Tecnológica, 2007. Cap. 12, p. 287-302.

PEREIRA NETO, J.T.Gerenciamento de Resíduos Sólidos em Municípios de Pequeno Porte. Revista Ciência e Ambiente, número 18, Santa Maria-RS, 1999.42-52p. POLETO, C. Introdução ao gerenciamento ambiental. Rio de Janeiro: Interciência, 2010. $354 \mathrm{p}$. 